\title{
Research on the Influence Factors of Product Design in Complex Product Systems
}

\author{
Xiuhong Wang and Jing Suo* \\ School of Management Science and Engineering, Zhengzhou University of Aeronautics, Zhengzhou, China \\ Corresponding Email: 635013329@qq.com
}

\begin{abstract}
With the development of society and economy, CoPS play an increasingly important role in a country; it is obvious and urgent to research the product design in CoPS. Compared with the traditional ordinary products, this paper analyzes the requirements of CoPS product design and the main influence factors, and use a innovative mind to make the product design, in order to meet customer demand and reduce the risk of design, then put forward the influence factors in the design process. So, it can help enterprises improve product design process and provide favorable support to increase economic benefit.

Keywords. CoPS, product design, influence factors .
\end{abstract}

\section{Introduction}

Since the concept of CoPS generated, which scope is very broad, and the definition of CoPS is very fuzzy. Until the end of the 1990s, CoPS had a more clear understanding. Some scholars believed that CoPS usually need higher research costs, more complex technology, more specific requirements to customers, single product or system, or other facilities, and so on [1]. Related research scholars in domestic believed that CoPS is a kind of innovation activity, which has characteristics of high investment, high risk and high technique [2]. With the rapid development of science and technology, international competition is increasingly fierce, and the structure of CoPS is becoming more and more complicated, of cause products is also becoming more and more integrated and complicated. So, it is necessary to analyze the factor of product design in CoPS.

Chen Ming [3] pointed out that the complex product generally use high and new technology, and each subsystem have a more complex constraint relationship in various parts. Chen Jin and Tong Liang [4] study the management of CoPS innovation compared with the traditional management, from the high cost of custom, the subsystem structure, single production requirements to summarize the complexity of CoPS, and from five aspects such as product evolution characteristics to carry out innovation management. Ou Song [5] through the study of complex system structure, constructs a CoPS model of multiple views, and use this model to illustrate the concurrent engineering of product design.

Although many scholars do the in-depth research for CoPS, studying the product design this part of CoPS is very few. Therefore, research on the factors of product design help the enterprise have a good understanding in the products, then they will have a better grasp to the needs of society, in this way to recognize market requirement and meet customers satisfaction, at the same time, it can also avoid the waste of money. So, analyzing the factors of product design is imperative.

\section{COPS and product characteristics}

On the basis of some scholars' research, summarizing the characteristics of CoPS. From the production type, CoPS is custom, and it needs to negotiate with customer to determine the product requirements, then conduct customized production [6]. From the production quantity, which belongs to a single small batch production, because of the uncertainty of CoPS and inconsistency requirements, therefore it does not have scale production conditions [7]. From the product technique, which belongs to technology-intensive, its products cover many aspects of knowledge, and it also has complex function and interface [8].

CoPS product characteristics can be learned from analysis of CoPS, which mainly includes: complex product structure, diverse performance and stronger competitiveness this three aspects, from this perspective to grasp the factors analysis of product design is very effective and feasible.

\section{CoPS product design requirements}


After analysis of the product characteristics of CoPS, obviously, to study the product design is a activity that full of challenges and risks. It is influenced by many factors whether product design can achieve success or not, such as product performance, the degree of meeting customer demand, and so on. In order to reduce the risk of product design as much as possible, which need to analyze the requirements of CoPS product design, so this paper from the product performance and the degree of meeting customer demand this two aspects to discuss.

\subsection{Excellent product performance}

The requirements of CoPS product design must consider the product performance, this article from the product function, quality, efficiency, and manufacturing process requirements to consider the necessary factors in product design. Function is an important sign, the quality is customers should consider the core factor besides function, what's more, the final purpose of CoPS product design is to get benefit, and efficiency directly reflect the interests of enterprise, which should not be ignored. In order to make product more innovative and get more customers resources, enterprises must start from the manufacturing process to improve their product, which is a basic way to meet the requirements of product design.

\subsection{Degree of meeting customer demand}

The main purpose of design and trial-produce new products is to meet changing customer demand and obtain a better economic benefit. At the same time, design and trial-produce new products have to make profits as the premise. Only when there are society needs, they will have chance to get profits. What's more, enterprise usually need to consider the long period development, not just the current needs, so, they should make different measures to adapt society need in time, that is to say, through meeting the customer demand and greatly improve customer satisfaction, it can achieve the requirements of CoPS product design.

\section{Analysis factors of product design}

Through the above analysis, in CoPS product design factors analysis, this paper from the product hierarchy, the complexity of design techniques, the reliability of resource equipment and product innovation this four aspects to analyze the influence factors of product design.

\subsection{Product hierarchy}

The complexity of CoPS product is mainly embodied in the product has a hierarchical structure, the composition of complex products from low to high is divided into three levels, that is, component, system and integration. There are coupling relationship in each hierarchy, therefore, CoPS product own its inherent physical function, which reflect in product availability and functionality, and the function module of a product is usually composed of a multi-level hierarchical structure. At the same time, there is a kind of dynamic information interaction between each function module and parts, and the information feedback is also a multi-level hierarchical structure.

\subsection{Complexity of design techniques}

The stability of technique and difficult index are important index to measure the complexity of design techniques. Design techniques is a core factor of product design, which directly reflect the technical requirements of product design process, of cause, the higher products require, the more complex technology is. Technology stability refers to the deviation degree to its normal level design technology in the design phase, the difficult index refers to the biggest difficulty to meet the product design requirements. To ensure the product design is excellent, which need to guarantee a good stability and overcome the difficult index of the product.

\subsection{Reliability of resources equipment}

The input of resource and capital is enormous in CoPS [9], especially in product design, so, it is necessary to ensure the availability and reliability of resources, here mainly contain capital flow and system equipment. On the one hand, the capital is an important factor in enterprise, which is to guarantee a normal running of the system. Product design requires repeated trial, and the cycle time of CoPS product is very long and investment is large, so there are gaps about capital in the product design stage. Therefore, enterprise need to carry out reasonable budget and capital investment to guarantee product design stage can develop successfully. On the other hand, CoPS equipments usually have great complexity and integration, it needs various complex equipments work together in product design, especially design quality and innovation analysis are technical personnel through equipments running to accomplish. So, it is necessary to ensure the integrity equipment. In conclusion, to guarantee reliability of resources equipment is an indispensible factor for enterprise. 


\subsection{Product innovation}

There is some difference between CoPS products and traditional products, CoPS will pay more attention to product innovation, actually, product innovation is the integration between technical knowledge and market demand, in this way to get a innovative product, through the effects of product for some customers, then continue to improve the product and further innovation, until to get the satisfied products. The specific innovation design process is shown in Figure 1.

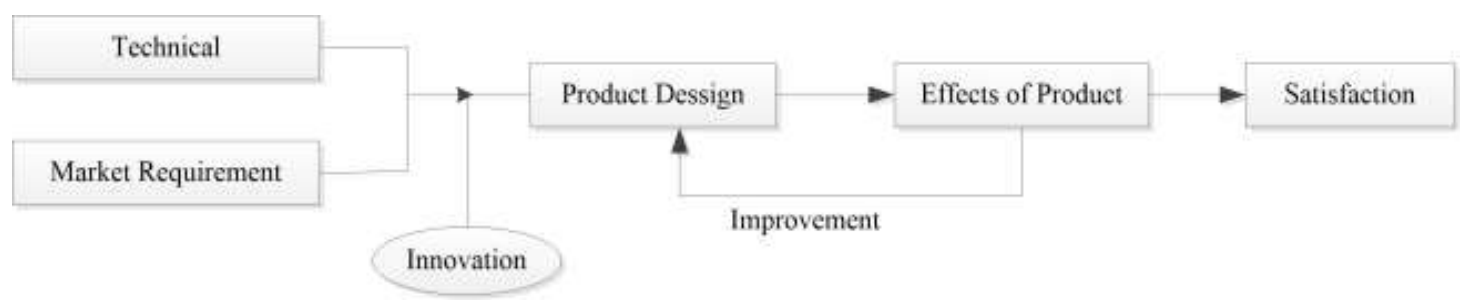

Fig. 1. Innovation design process.

\section{Prospect of research}

Compared with ordinary products, CoPS products design process is more complex, and capital inputs and product design cycle is greater than the ordinary products. Through the study of product design process, this paper analyzes the characteristics of CoPS product design factors in detail, and proposed four factors should be considered in the stage of product design, which is a very meaningful research. Through the concrete analysis of influence factors for CoPS, enterprise will get some useful advances to make a great product design, so it is very necessary to do this research. There is no doubt that there are still many issues deserve further research in the process of CoPS product design, such as the connection between the product design factors, how to realize the integration of product design process, and so on. Through in-depth study of these problems, enterprise can improve the success rate of product design, and make their product own a stronger competition in the market, so as to reduce the design risks and add economic benefits.

\section{Acknowledgment}

Thanks for the fund provided Humanities and social science project of Henan Provincial Department of Education (Grant No.2015GH-039) and Key scientific research projects of Henan high school (Grant No.16A630063)

\section{References}

1. K.L. Hansen, H. Rush. Hotspots in Complex Product Systems: Emerging Issues in Innovation Management. Technovation, 1998, 18(9): 555- 561.

2. X.G. Gong, X. Song, Q.X. Zhu. the Cost Management of Technological Innovation System based on System Dynamics. Journal of Technology and Management,2009(4):128-131.

3. M. Chen, Y. Chen, B.S. Chen. the Research of Complex products in Technology Risk Management. Journal of Manufacturing Automation, 2005, 27(10): 6-16.

4. J. Chen, L. Tong, J.Z. Huang. Complex Product Systems Innovation to Traditional Management challenges. Journal of Science and Technology Management, 2004, 09: 47-51.

5. S. Ou, M.L. Zhong, D.Y. Qi, Q.J. Zhou. Multiple View Model of Complex Product Systems. Journal of Jinan University, 1998, 01: 150-156.

6. M. Hobday, T. Brady Rational vs. soft management in complex software: lessons from flight simulation. International Journal of Innovation Management, 1998, 2(1): 1 - 43.

7. K. Hansen, H. Rush. Hotspots in complex product systems: Emerging issues in innovation management.Technovation, 1998, 18 (9): 555- 561.

8. Z.D. Chen, K.Y. Wang. the Complexity of Complex Product Systems to Study the Effect of Knowledge Management. Journal of Science and Technology Management, 2007, 05: 101-105.

9. J. Chen, L. Tong, Y. Gong. Research of Complex Product Systems Innovation Evaluation Index System. Journal of Management Research and Development, 2003, 04: 59-65. 